\title{
Para comprender el desarrollo del Sistema Educactivo Inclusivo
}

\begin{tabular}{c} 
Mel Ainscow \\
\\
\hline${ }^{1}$ School of Education. \\
Universidad de Manchester
\end{tabular}

Reino Unido

mel.ainscow@man.ac.uk 


\section{Resumen}

Hace ahora una década que la Conferencia de Salamanca sobre Necesidades Educativas Especiales aprobó la idea de la educación inclusiva. El documento internacional con toda probabilidad más importante en el campo de las necesidades especiales, la Declaración de Salamanca, afirma que las escuelas ordinarias con una orientación inclusiva son "el medio más eficaz de combatir las actitudes discriminatorias, construir una sociedad integradora y lograr la educación para todos". Además, sugiere que estas escuelas pueden "proporcionar una educación efectiva para la mayoría de los niños y mejoran la eficiencia y, en definitiva, la relación costo-eficacia de todo el sistema educativo" (UNESCO, 1994).

Durante estos últimos 10 años ha existido una actividad considerable en muchos países para cambiar las políticas y prácticas educativas hacia una dirección más inclusiva (Mittler, 2000). En este trabajo, presento datos que provienen de la investigación llevada a cabo en esta década para tomar en consideración lo que debe ser hecho, con el objeto de continuar los avances realizados hasta este momento. En particular, considero la pregunta “¿Cuáles son las "palancas" que pueden impulsar a los sistemas educativos hacia una dirección inclusiva?"

Palabras clave: necesidades especiales, educación inclusiva, políticas inclusivas, investigación educativa 